For example, Hambrecht \& Hafner's (1996) study of 232 first-episode cases of schizophrenia reported large and consistent differences in age at onset between those who misused alcohol and other drugs and those who did not. The age at onset of the first psychotic symptoms was 6-8 years earlier in drug users and 1-4 years earlier in those who misused alcohol. They also found that alcohol and drug misusers had more positive psychotic symptoms and more social problems than those who had not misused drugs.

These results differ from those of Kovasznay et al's (1993) study of substance misuse and its correlates among newly incident cases of psychosis. They found similarly high rates and patterns of substance misuse among their patients with schizophrenia ( $n=76$ ): $50 \%$ of males and $17 \%$ of females had a history of substance misuse disorders, with alcohol and cannabis being the most commonly misused drugs. However, they did not find any differences in age at onset of psychotic disorders between those who had and those who had not misused drugs, and there was no suggestion that a difference went undetected because of low statistical power. Similar results emerged from Cuffel et al's (1993) analysis of substance misuse among 231 cases of schizophrenia identified in the Epidemiologic Catchment Area study. Substance misusers in this study did not differ from non-misusers in age at onset, treatment history or the prevalence of psychotic symptoms.

In the face of these conflicting results it is difficult to decide upon the nature of the relationship, if any, between cannabis use and the age at onset, premorbid personality, or the prevalence of psychotic symptoms in people with schizophrenia. None of this exculpates cannabis use from being a possible risk factor for psychosis, or its continued use as a behaviour that may exacerbate the course of schizophrenia.

Cuffel, B. J., Helthoff, K. A. \& Lawson, W. (1993)

Correlates of patterns of substance abuse among patients with schizophrenia. Hospital and Community Psychiatry. 44. 247-251.

Hambrecht, M. Mafner, H. (1996) Substance abuse and the onset of schizophrenia. Biological Psychiatry, 40, 1155-1163.

Kovaeznay, B., Bromet, E., Schwartz, J. E., et of (1993) Substance abuse and onset of psychotic illness. Hospital and Community Psychiatry, 44, 567-571.

W. Hall National Drug and Alcohol Research Centre, The University of New South Wales, Sydney 2052, Australia

\section{Depressive delusions and the general election}

Sir: I would like to report the case of an 80year-old man, with no previous psychiatric or significant medical history, who six days after the landslide general election defeat of the Conservative Party developed depressive delusions that because of the Labour victory his investments were now worthless and his business was going to fail leaving him and his family penniless and forcing him to sell his house. He was agitated and extremely distressed by these ideas and believed his wife and adult daughter should kill themselves to avoid the shame of penury. He was in clear consciousness with no cognitive impairment. Mild symptoms of depression had started two weeks before with loss of energy and interests and sleep disturbance; these were treated with fluoxetine, to which he had shown no response. He was admitted to hospital but became acutely confused. Investigations showed hyponatraemia due to the syndrome of inappropriate antidiuretic hormone secretion, probably secondary to the fluoxetine. The delirium improved rapidly with discontinuation of fluoxetine and fluid restriction and he was left with mild depressive symptoms, but no further abnormal beliefs about the election. He made sense of his delusions by saying he had confused Tony Blair with Tony Benn! The political change going on around him clearly influenced the content of his delusions and may have affected the course of his illness. He was convinced he would not have been so hopeless about his future if there had been a hung parliament.

G. Yorston South Buckinghamshire NHS Trust, Shrubbery Road, High Wycombe, Buckinghamshire HPI3 6PS

\section{Role of GPs in service provision for people with schizophrenia}

Sir: Lang et al's (1997) interesting analysis is marred by a number of features. First, the sample data are not clearly defined. It would appear that the 193 patients who took part in the study were psychiatric outpatients. A recent review in my own practice found that more than one-third of those with schizophrenia were not known to the local psychiatric services.

Second, the difficulties in reviewing the entries in the case notes, although understandable, should have been dealt with by employing a GP researcher who would have been able to interpret the sometimes arcane way in which material is entered. Despite that, however, to recommend that there should be a standardised method for recording consultations in primary care is extraordinary. This shows a total lack of appreciation of the problems facing GPs. What is needed is hinted at later in the paper, where it is suggested that community psychiatric nurses (CPNs) should be involved. Our own practice is now undertaking a review of all patients by our locality attached CPN as a pilot to undertaking the same work throughout the six practices in our small locality. The aim of this review is to enter in the notes a care plan for each patient, with clear indications as to who the keyworker will be.

My other concern is that Lang et al fail to recognise a further major problem in primary care. At present, notes are kept separately by health visitors and by nurses in the majority of practices, with the result that there is no comprehensive primary care record. In the case of people with schizophrenia this can mean that contact for depot injections is undertaken by a nurse and recorded separately. In some cases the family will be supported by a health visitor, and again separate records may be kept.

This fragmentation, which is part of the inheritance of a divided primary care service, needs to be tackled along with developing seamless care for this group of patients. Lang et al's central finding that problem patients have a past history of drug misuse is, however, an important and helpful finding, although it is not clear whether this includes alcohol remaining as one of the problem areas in older patients with schizophrenia.

Lang, F. H., Johnetone, E. C. \& Murray, G. D. (1997) Service provision for people with schizophrenia: II. Role of the general practitioner. British journol of Psychiatry, 171, 165-168.

R. J. Simpson Bridge of Allan Health Centre, Fountain Road, Bridge of Allan FK9 4EU

Author's reply: Dr Simpson is right to draw attention to lack of contact which many people suffering from schizophrenia have with the local psychiatric services. In the companion paper to the one Dr Simpson comments upon (Lang et al, 1997) we clearly define our study populations. The 193 patients whom we studied had all had at least one admission to the Royal Edinburgh 
Hospital in the five years prior to the study commencing. Less than half $(49 \%)$ of our study sample were in regular contact with a psychiatrist (see Lang et al, 1997, Table 1).

We would agree with Dr Simpson that the development of a comprehensive primary care record for patients with schizophrenia would be a welcome advance. We are of the opinion, however, that if people other than GPs are to contribute to such records, it is essential that a standardised method of recording consultations in the primary care setting is devised.

We agree with Dr Simpson that alcohol misuse in both younger and older people with schizophrenia significantly contributes to the difficulties which arise in patient management, but we did not find that a past history of alcohol misuse was independently related to whether or not a patient was considered by the GP as causing a problem for the practice.

Lang, F. H. Forbes, J. F., Murray, G. D., et al (1997) Service provision for people with schizophrenia: I. clinical and economic perspective. British journal of Psychiatry, 171 . 159-164.

F. H. Lang Department of Psychiatry, Kennedy Tower, The Royal Edinburgh Hospital, Morningside Park, Edinburgh EHIO 5HF

\section{Lethal lithium poisoning with sustained-release preparations}

Sir: Cookson (1997) and Moncreif (1997) have mentioned serious toxicity and death as a consequence of lithium intoxication. It would be useful to stress that more serious poisoning usually occurs after intoxication by sustained-release lithium preparations.

In 27 years of lithium medication in Southern Moravia, four cases of lethal intoxication have been reported, three of them suicides. All three patients took a high dose of the sustained-release lithium product. In two cases, the approximate doses were known ( 50 and $70 \mathrm{~g}$ lithium). In one case, the dose has not been established. Two of the patients died on the fifth day and the other died on the 12th day after taking the lethal dose of lithium. In one of the patients, the autopsy revealed undissolved lithium tablets in the stomach and the remains of tablets in the intestines, despite a gastric lavage. In another patient, high levels of lithium (34 and $11.3 \mathrm{mmol} /$, respectively) were found in the gastric lavage returns on the first and second days.
It seems that the advantage of sustained-release preparations becomes a disadvantage during intoxication. Standard gastric lavage does not remove the lithium tablets from the gastro-intestinal tract, and if they are not removed, lithium is released for a surprisingly long period of time.

One effective method, proposed by Smith et al (1991), is gastric lavage with polyethyleneglycol, which can prevent the absorption of up to $67 \%$ of the ingested lithium. Other authors recommend gastroscopy combined with aspiration, under visual control, or enterotomy to remove the tablets in addition to lavage (Olson, 1991; Ševčík et al, 1994).

Cookson, J. (1997) Lithium: balancing risks and benefits. British journal of Psychiatry, 17I, 120-124

Moncrieff, J. (1997) Lithium: evidence reconsidered. British Journal of Psychiotry, 171. 113-119.

Olson, K. R. (1991) Lithium. In Intensive Care Medicine (eds J. M. Rippe, R. S. Irwin. J. S. Alpert, et al). Boston, MA: Little. Brown and Co.

Smith, S. W., Ling, L. J. \& Halstenson, C. E. (1991) Whole bowel irrigation as a treatment for acute lithium overdose. Annals of Emergency Medicine, 20, 536-539.

Sowzik, P., Hrdilickea, M., Novotna, J., et al (1994) Current developments in the treatment of lithium intoxications. In Proceedings of the 7th European Congress on Intensive Core Medicine, pp. 903-906. Bologna: Monduzzi Editore.

M. Hrdlička Department of Psychiatry, 2nd

Medical School of Charles University, Vúvalu 84, 150 18 Prague, Czech Republic

P. Sevčik Department of Anaesthesiology, Medical School of Masaryk University, Brno, Czech Republic

\section{Tardive dyskinesia and CYP2D6 polymorphism in Chinese}

Sir: Epidemiological studies have shown a lower prevalence rate of tardive dyskinesia among Chinese than Caucasian subjects receiving neuroleptics (Swartz et al, 1997). A pharmacogenetic factor may underlie this cross-cultural difference. The study by Armstrong et al (1997) which suggests an association of neuroleptic-induced movement disorders, including tardive dyskinesia, with genetic polymorphism of CYP2D6 supports this hypothesis. About $7 \%$ of the Caucasian population lacks the CYP2D6 enzyme (i.e. poor metabolisers) compared with about $1 \%$ of the Chinese (Brosen, 1996). The majority of these Caucasian poor metabolisers have a mutant allele 2D6(B), which contains a splicing defect that is not present in a large section of the Chinese population (Brosen, 1996). New mutations have recently been reported, including the $\mathrm{Cl}$ $T_{2938}$ variation that results in one amino acid difference (R296C). This mutation, postulated to be in the putative substrate-recognition site of the CYP2D6 enzyme, also shows ethnic differences in its distributions $(26 \%$ in Caucasians, $19 \%$ in Chinese) (Wang et al, 1995). It has also been reported to be associated with Parkinson's disease (Tsuneoka et al, 1993). This is intriguing because patients with a family history of Parkinson's disease have a high risk for developing tardive dyskinesia (Swartz et al, 1997). This suggests an association of a vulnerability to tardive dyskinesia with the R296C mutation - a possibility that merits further investigation.

Armetrong, M., Daly, A. K., Blennerhassett, R., et of (1995) Antipsychotic drug-induced movement disorders in schizophrenics in relation to CYP2D6 genotype. British journal of Psychiatry, 170. 23-26.

Brosen, K. (1996) Drug-metabolism enzymes and therapeutic drug monitoring in psychiatry. Theropeutic Drug Monitoring, 18. 393-396.

Swartz, J. R., Burgorme, K., Smith, M., et al (1997) Tardive dyskinesia and ethnicity: review of the literature. Annals of Clinical Psychiatry, 9, 53-59.

Touneoka, T., Matsuo, Y., Takeuchi, H., et ol (1993) A novel cytochrome P450 IID6 mutant gene associated with Parkinson's disease. Journal of Biochemistry. I14, 263-266.

Wang, S. L., Lai, M. D., Lai, M. L., et al (1995) R296C and other CYP2D6 mutations in Chinese. Pharmocogenetics, 5. 385-388.

S.-A. Chong Woodbridge Hospital \& Institute of Mental Health, 10 Buangkok Green, Singapore 539747

\section{Evidence-based psychiatry}

Sir: The practice of evidence-based medicine has been defined as the conscientious, explicit and judicious use of current best evidence in making decisions about the care of individual patients (Sackett et al, 1996). A systematic review of randomised controlled trials can be a very useful source of evidence. The key point about a systematic review is that it has a method section which clearly states how the primary studies were identified and selected for inclusion in the review, and how their quality was assessed (Oxman et al, 1994). Neither the article by Moncrieff (1997) nor the commentary by Cookson (1997) provided this information, despite their inclusion under the heading of 'evidence-based psychiatry'. It is therefore difficult to assess the validity of these articles, and to what extent the authors attempted to avoid bias. 